\title{
Seismic nonlinear vibration control algorithm for high-rise buildings
}

https://doi.org/10.1515/nleng-2021-0048

Received Sep 15, 2021; accepted Sep 15, 2021

\begin{abstract}
It is necessary to study the seismic problem of buildings and structures for various safety reasons. Such as prevent and to reduce the damage caused by earthquakes to the greatest extent possible, research feasible analysis methods, and simulate the performance of the structure under earthquake action by computer, to keep its design performance in future earthquake action, and to ensure the safety of people's lives and property. The seismic design based on nonlinear vibration control is proposed. SAP2000 structure analysis software is used to establish the seismic structure model, foundation isolation model, and floor isolation model of a 15-story large chassis frame structure, the nonlinear time-history analysis of the three models under the action of multiple and rare earthquakes is carried out, and the period, displacement and acceleration of the isolated structure and the aseismatic structure are compared. The results show that, under the action of multiple earthquakes, the base shear of foundation isolation is $1208.06 \mathrm{kN}$, and the floor isolation is $926.43 \mathrm{kN}$, which are 0.37 and 0.3 of the base shears of the aseismatic structure, respectively. Under the action of rare earthquakes, the base-isolation shear is $4039.59 \mathrm{kN}$, and the story isolation shear is $3119.99 \mathrm{kN}$, which are, respectively, 0.4 and 0.31 of the base-isolation shears of the aseismatic structure. This method provides a reliable evaluation for nonlinear seismic response analysis of large complex high-rise buildings and provides an effective reference.
\end{abstract}

Keywords: Nonlinear; high-rise isolation structure; seismic performance; aseismatic structure

\footnotetext{
${ }^{\star}$ Corresponding Author: Mohammed Wasim Bhatt: Central University of Punjab, Bathinda, India;

Email: wasimmohammad71@gmail.com

Qian Liu: Anhui Vocational and Technical College, Anhui Hefei, 230061, China

Weikang Zhang: Communication Engineering Major, Wentian College, Hohai University, Anhui Heifei, 243000, China

Ajit Kumar: Business Analytics, JBS, JIIT University, Noida, India
}

\section{Introduction}

Earthquake is a sudden type of natural disaster, strong earthquake in an instant can cause landslides, river diversion, house collapse, bridge collapse, dam break to people's lives, and property causing serious harm. Earthquake caused by the destruction of buildings and engineering facilities and the resulting secondary disasters, which is an important cause of casualties and economic losses. China is a country with many earthquakes, and the earthquake zone of more than 6 degrees is almost all administrative regions of the country, the most fundamental preventive measure to reduce the earthquake damage is to adopt a reasonable seismic design method, improve the earthquake resistance of the building, and prevent the building from serious damage and collapse. According to statistics, the earth's average annual magnitude of 8 or more, the epicenter intensity of more than 11 degrees of destructive earthquakes 2 times; magnitude of 7 or more, the epicenter intensity of more than 9 degrees of large earthquakes about 20 times; there were more than 150,000 felt earthquakes with a magnitude above 2.5 [1, 2]. The earthquake caused large casualties and economic losses to the social economy and people's heart has brought a large negative effect, so that people cannot bear. To prevent and reduce the damage of buildings and structures caused by the earthquake to the greatest extent, research feasible analysis methods, and simulate the performance of the structure under the earthquake action by computer, to keep its design performance in the future earthquake action, to ensure the safety of people's life and property, it is necessary to study the seismic problem of buildings and structures. Generally, the research of seismic design methods of structures mainly includes the following four aspects: The determination of design earthquake action and the selection of design ground motion parameters; structural seismic response analysis method; seismic damage assessment of structures: a reasonable and convenient design method [3-5].

At present, most of the world's seismic design codes adopt the three-level seismic fortification criterion of "not bad in small earthquakes, repairable in medium earthquake, and not bad in large earthquakes”. This design idea

This work is licensed under the Creative Commons Attribution 4.0

Ә Open Access. (c) 2021 Q. Liu et al., published by De Gruyter. (CC) BY License 
has also achieved great success in practice. However, this kind of aseismatic design thought is to protect the life safety as the main fortification goal, although it can make the main structure do not collapse to protect the life safety in the big earthquake, but it may cause the loss of the normal function of the structure under the small earthquake and cause substantial economic loss. Especially with the development of social economy, the cost of the interior decoration, nonstructural components, and information technology equipment of the structure often greatly exceeds the cost of the structure itself, and such loss will become more serious. For example, the 1989 Loma Prieta earthquake (M7.0) in the United States killed and injured more than 4,000 people, but caused economic losses of us $\$ 6$ billion; The 1994 Northridge earthquake (M6.7) killed 57 people and caused $\$ 17$ billion in economic damage: In 1995, The Kobe earthquake in Japan (M7.2), more than 5,500 people died, caused economic losses as high as $\$ 100$ billion, the recovery and reconstruction work after the earthquake lasted more than two years, costing nearly $\$ 100$ billion. These earthquake damages indicate that with the further development of social economy and the sharp increase of population density in big cities, the economic losses caused by earthquakes will be increasingly large. The high uncertainty of earthquake disasters and the new characteristics of great economic losses caused by modern earthquake disasters have caused profound reflection on the existing ideas and methods of seismic design in the world's earthquake engineering community, it is necessary to further explore more perfect ideas and methods of structural aseismic design, and it is also the basis of controlling earthquake disaster loss. Zhang et al. developed an innovative solution for vibration suppression in high-rise buildings. An infinite size system model has been proposed to describe a tall building structure with large inertial loads based on the Hamilton principle [6]. Song et al. based on the system model and the direct method using Lyapunov, a boundary controller is proposed for the closed-loop system with uniform boundaries in the time domain. Finally, by using the intelligent structure lab platform generated by Quancer, we conducted a set of experiments and found that the designed approach was effective [7]. According to Kamaludin et al., structural control can be divided into the following four categories according to whether external energy is needed: (1) Passive Control: it does not need external energy to drive, and simply relies on the interaction between control device and structure to provide control force; (2) Active Control: external energy is needed to drive the actuator, and the Control force is determined by the observed excitation and feedback of the structure; (3) Semi-active Control; Mainly passive control, only when the structural response reaches the limit value, a small amount of energy is applied to make the control system switch working state, its hardware is simple, no online calculation, stability and reliability; (4) Hybrid Control: both active and passive control are applied to the structure, and the response is analyzed as a whole to overcome the application limitations of pure passive control, reduce the control force and reduce the power, volume, energy and maintenance costs of external control equipment, and increase the reliability of the system. The structural control scheme is shown in Figure 1 below [8]. Yao Q. et al. studied the limit of stroke length of mass block and proposed the design steps and algorithm of variable gain feedback control with ATMD system [9]. Lu et al. studied the application of Kalman filtering method in ATMD system based on Pade assumption to deal with delay problem [10]. Kumar et al. proposed a simple method for ATMD design for wind vibration control of high-rise buildings: Based on the SDOF structural model and gaussian white noise assumption of generalized fluctuating wind, the control force gain was parameterized to obtain the gain solution in the frequency domain with the design goal of minimizing the displacement of the structure's top floor [11]. Solovyova et al. proposed a similar control system for towering structures. The gas pulse generator generates pulse control force through air injection or other ways, which can control the peak response of the structure. The control effect is good, but the pulse force control is difficult. In addition, prestressed oblique support is installed on the frame, torsional vibration gyroscope controlling the suspension cable, and strong electromagnetic field is used to control the dam sprinkled with iron powder, etc. [12]. Bharti et al. proposed a variable friction damper, which uses a friction rod rigidly connected to the support of the structure and determines the damping force on the friction surface by adjusting the sliding distance. In addition, a column liquid damper (TLCD) with adjustable baffle hole based on passive control device has emerged [13]. Lu et al. studied the semi-active stiffness control system [14]. Monika et al. respectively studied semi-active er dampers 168.69; Spencer et al. studied semi-active MR Dampers [15]. Li et al. studied the semi-active liquid damper test equipment and realized the control by changing the amount of liquid through the shunt loop, and the linear effect could be achieved by using nonlinear damper through proper adjustment of the control valve [16].

On the basis of the current research, the seismic design based on nonlinear vibration control is proposed. The research results show that, under the action of multiple earthquakes, the base shear of foundation isolation is 1208.06 $\mathrm{kN}$ and the floor isolation is $926.43 \mathrm{kN}$, which are 0.37 and 0.3 of the base shears of the aseismatic structure re- 

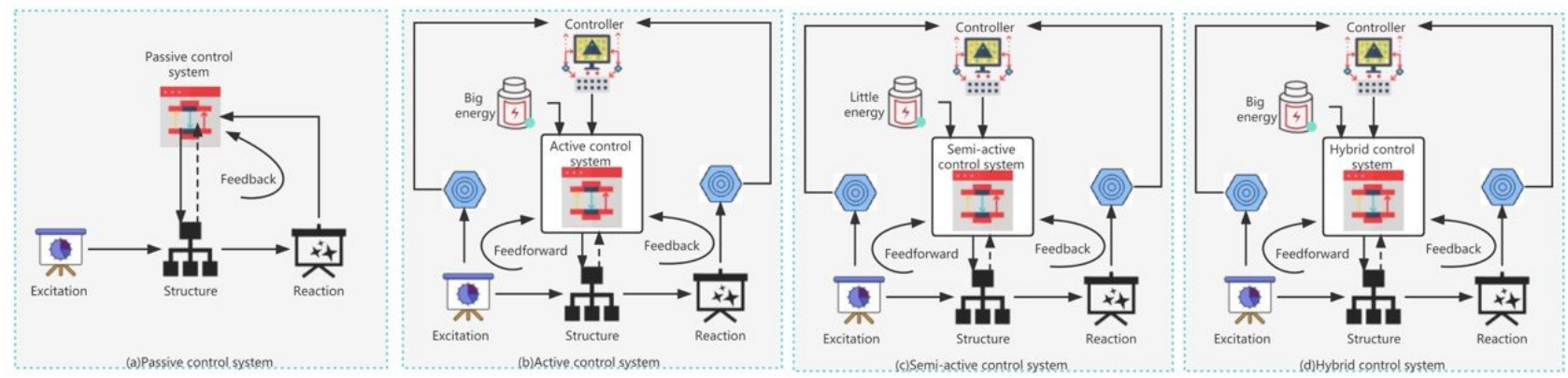

Figure 1: Examples of each control system

spectively. Under the action of rare earthquakes, the baseisolation shear is $4039.59 \mathrm{kN}$, and the story isolation shear is $3119.99 \mathrm{kN}$, which are, respectively, 0.4 and 0.31 of the base-isolation shears of the aseismatic structure. The effect of floor isolation is slightly lower than that of the base isolation structure, so it is slightly better than that of the base isolation structure, and far better than that of the seismic structure. The seismic safety has been effectively improved, but whether the seismic intensity level can be reduced still needs further study.

\section{Research methods}

\subsection{Structural dynamic equation}

The three models of the structure all adopt multiparticle system shear calculation model, among which the storyseparated structure model. The quality of each layer is $m_{1}$, $m_{2}, m_{n}$, the stiffness of each layer is $k_{1}, k_{2}, k_{n}$, the damping is $c_{1}, c_{2}, c_{n}$, the dynamic balance equation is as follows (1):

$$
[M]\{\ddot{x}\}+[c]\{\dot{x}\}+[k]\{x\}=-[M]\{I\} \ddot{x}_{g}
$$

Where, $m_{i}$ is the quality of the $i$ floor, $M$ is the mass matrix, the equation is as follows (2).

$$
M=\left[\begin{array}{cc}
m_{1} & 0 \\
0 & m_{n}
\end{array}\right]
$$

$k_{i}$ is the stiffness of layer $i, K$ is the stiffness matrix, the equation is as follows (3)-(6).

$$
\begin{gathered}
K=\left[\begin{array}{cccc}
k_{1}+k_{2} & -k_{2} & & \\
-k_{2} & k_{2}+k_{3} & -k_{3} & \\
& \ldots & \ldots & \ldots \\
& -k_{n-1} & k_{n-1}+k_{n} & -k_{n} \\
& & -k_{n} & -k_{n}
\end{array}\right] \\
C=a[M]+b[K]
\end{gathered}
$$

$$
\begin{gathered}
a=\frac{2\left(\frac{\xi_{i}}{\omega_{i}}-\frac{\xi_{i+1}}{\omega_{i+1}}\right)}{\frac{1}{\omega_{i}^{2}}+\frac{1}{\omega_{i+1}^{2}}} \\
b=\frac{2\left(\xi_{i+1} \omega_{i+1}-\xi_{i} \omega_{i}\right)}{\omega_{i+1}^{2}-\omega_{i}^{2}}
\end{gathered}
$$

Where, $C$ is the damping matrix $\xi_{i}, \omega_{i}$ is the damping ratio of the $i$ mode, natural frequency; $\ddot{x}_{g}$ is ground motion acceleration; $\{x\}$ is the displacement vector $\{x\}=\left\{x_{1}, x_{2} \cdots x_{n}\right\}^{T} ;\{\dot{x}\}$ is the velocity vector, $\{\dot{x}\}=$ $\left\{\dot{x}_{1}, \dot{x}_{2} \cdots \dot{x}_{n}\right\}^{T} ;\{\ddot{x}\}$ is the acceleration vector, $\{\ddot{x}\}=$ $\left\{\ddot{x}_{1}, \ddot{x}_{2} \cdots \ddot{x}_{n}\right\}^{T}$.

\subsection{Calculation model and basic parameters}

\section{(1) Model structure}

To study the characteristics of foundation isolation and floor isolation of a large chassis structures with vertical stiffness change, a single tower frame structure of a building was analyzed. The big chassis is 3 layers, the height is $4500 \mathrm{~mm}$, the concrete strength grade is C35, the column section size is $650 \times 650 \mathrm{~mm}$. The beam section size is $300 \times 600 \mathrm{~mm}$. The height is $3000 \mathrm{~mm}$, the concrete strength grade is $\mathrm{C} 30$, the column section size is $600 \times 600 \mathrm{~mm}$, and the beam section size is $300 \times 600 \mathrm{~mm}$. The thickness of the structural plate is $150 \mathrm{~mm}$, the size of the structural column network is $4800 \times 4800 \mathrm{~mm}$, the longitudinal is $28800 \mathrm{~mm}$, and the transverse is $24000 \mathrm{~mm}$. The seismic fortification

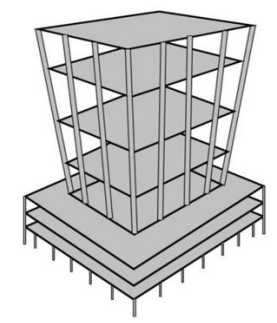

Figure 2: Analysis model of frame structure 
Table 1: Performance parameters of isolation support

\begin{tabular}{|c|c|c|c|c|c|c|c|c|c|}
\hline \multirow[t]{2}{*}{ Model } & \multirow{2}{*}{$\begin{array}{l}\text { Design } \\
\text { bearing } \\
\text { capacity } \\
\text { /kN }\end{array}$} & \multirow{2}{*}{$\begin{array}{c}\text { Effective } \\
\text { diameter } \\
\text { /mm }\end{array}$} & \multirow{2}{*}{$\begin{array}{c}\text { The actual } \\
\text { diameter } \\
\text { /mm }\end{array}$} & \multirow{2}{*}{$\begin{array}{c}\text { Bearing } \\
\text { height } \\
\text { /mm }\end{array}$} & \multicolumn{4}{|c|}{ Eigenvalues of $Y=100 \%$} & \multirow{2}{*}{$\begin{array}{c}\text { The } \\
\text { vertical } \\
\text { stiffness } \\
K_{V} \\
/\left(\mathrm{kN} \cdot \mathrm{m}^{-1}\right)\end{array}$} \\
\hline & & & & & $\begin{array}{c}\text { Equivalent } \\
\text { stiffness } K_{e q} \\
/\left(\mathrm{kN} \cdot \mathrm{m}^{-1}\right)\end{array}$ & $\begin{array}{c}\text { The yield } \\
\text { strength } \\
Q_{d} \\
/ \mathrm{kN}\end{array}$ & $\begin{array}{l}\text { Post-yield } \\
\text { stiffness } K_{d} \\
/\left(\mathrm{kN} \cdot \mathrm{m}^{-1}\right)\end{array}$ & $\begin{array}{c}\text { Equivalent } \\
\text { damping } \\
\text { ratio } H_{e q} \\
/ \%\end{array}$ & \\
\hline LRB600 & 4241 & 600 & 620 & 233 & 1681 & 90.2 & 929 & 26.5 & 2445 \\
\hline LRB700 & 5772 & 700 & 720 & 265 & 1961 & 122.7 & 1084 & 26.5 & 3259 \\
\hline
\end{tabular}

intensity is 8 degrees, the site category is the second type of site, and the design earthquake group is the third group, with characteristic period $T_{g}=0.45 \mathrm{~s}$. The structural floor live load is $2 \mathrm{kN} / \mathrm{m}^{2}$, the dead load on the beam is $7 \mathrm{kN} / \mathrm{m}^{2}$, and the wind pressure coefficient is 0.3 . Figure 2 shows the frame structure analysis model.

\section{(2) The basic parameters}

Base isolation and floor isolation are used in the structural calculation model. The selection of the isolation bearing is based on the maximum axial force at the bottom of the column does not exceed the limit value of the average compressive stress of the isolation bearing, and the maximum axial force at the bottom of the column is calculated according to the reduction of PKPM forceps intensity by one degree. The bearing layout principle is that the centroid of the isolation bearing coincides with the centroid of the section of the column.

In the structure, the maximum axial force at the bottom of the foundation isolation column is $5284 \mathrm{kN}$, so LRB700 is adopted, and this support is arranged at the bottom of each column. In SAP2000, rubber isolator in the nonlinear connection unit was used to simulate the isolation rubber bearing. The maximum axial force at the base of the tower column of the story isolation structure is $3475.9 \mathrm{kN}$, so LRB600 is adopted. This support is used at the base of the tower column on the first floor. The type of hysteresis curve is Kinematic. Various performance parameters are shown in Table 1. Two models of column LRB 700 and LRB 600 has been compared based on various performance parameters. It is clearly shown that the vertical stiffness of LRB 700 is higher compared to the LRB 600. Other parameters are briefly discussed in below Table 1 .

\subsection{Seismic wave}

The seismic response of the structure is not only related to the natural vibration period and damping, but also related to the magnitude of the earthquake action and its chang- ing characteristics with time, so it is essential to choose the appropriate seismic wave for the structure. This frame structure uses a real strong earthquake record, namely, the 1952 Taft wave. Amplitude modulation of seismic records according to specifications. In the process of time history analysis, the damping ratio of the frame structure is set as 0.05 , and the horizontal damping of the isolation bearing is set as 0.19. Under the action of frequent and rare earthquakes, Taft wave was input north-south $(\mathrm{Y})$ with a time interval of $0.02 \mathrm{~s}$, and the peak acceleration was adjusted to $70 \mathrm{~cm} / \mathrm{s}^{2}$ and $400 \mathrm{~cm} / \mathrm{s}^{2}$ respectively according to the specification.

\section{Result analyses}

\subsection{Natural vibration characteristics of structure}

The natural vibration period of a structure is an inherent property of the structure, which is related to the inherent stiffness and mass of the structure and has nothing to do with the dynamic excitation. The RITZ vector method was used for modal analysis of the structure model, and the first five modes were taken. The structure period and mass participation coefficient under different control schemes could be known by referring to Table 2 .

Under the three control schemes, the first period of the structure is translational in the $\mathrm{Y}$ direction, that is, the $\mathrm{Y}$ direction is the weak direction, the first three periods of the structure are dominated, and the natural vibration period of the isolation structure is more than twice the period of the seismic structure, it is far away from the characteristic period of the site, and the natural vibration period of the story-separated structure is $9.8 \%$ larger than that of the foundation isolation. 
Table 2: Period and mass participation coefficient

\begin{tabular}{cccc}
\hline $\begin{array}{c}\text { Vibration } \\
\text { mode }\end{array}$ & $\begin{array}{c}\text { The seismic } \\
\text { structure } T \\
/ \mathrm{s}\end{array}$ & $\begin{array}{c}\text { Base } \\
\text { isolation } T \\
/ \mathrm{s}\end{array}$ & $\begin{array}{c}\text { Layer } \\
\text { interval } \\
\text { shock } T \\
/ \mathrm{s}\end{array}$ \\
\hline 1 & 1.931 & 2.400 & 2.472 \\
2 & 1.874 & 2.386 & 2.460 \\
3 & 1.511 & 1.797 & 2.216 \\
4 & 0.700 & 0.685 & 0.502 \\
5 & 0.679 & 0.656 & 0.477 \\
\hline
\end{tabular}

\subsection{Analysis of displacement response}

Figure 3 interlayer displacement diagram under the action of multiple and rare earthquakes. Three different curves have been drawn in Figure 3 which represents ant seismic, foundational shock isolation and zone interval shock. Interlayer displacement has been displayed on $\mathrm{y}$-axis and $\mathrm{x}$ axis represents floor isolation. The intensity of zone shock is maximum for the given floor isolation. It can be seen from the figure: For seismic structures, the displacement between layers is small. For base isolation, the maximum interlayer displacement occurs at the bottom isolation layer, while the interlayer displacement of the superstructure is small, and the structure is mainly translational. The deformation of the layer isolation structure is concentrated at the isolation layer, and the displacement between the layers of the superstructure decreases and shows a linear relationship. In rare intensity, the angle limit of elasticplastic displacement between lower layers is $1 / 50 \times 3000=$ $60 \mathrm{~mm}$, and the maximum displacement of layer isolation

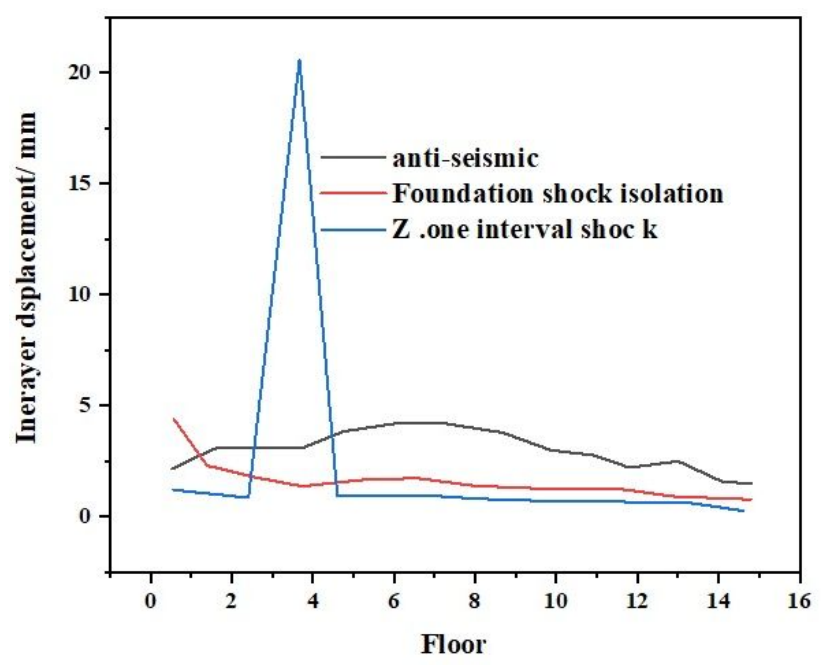

Figure 3: Interlayer displacement of Taft wave under multiple earthquakes is $50.36 \mathrm{~mm}$, which meets the requirements of the code. The displacement of the floor isolation is less than that of the foundation isolation, and the displacement of the isolation structure is $2 \sim 3$ times less than that of the seismic structure, indicating that after the adoption of isolation measures, the comfort level of the structure in the earthquake has been improved a lot. From the perspective of the interstory displacement, the isolation structure is better than the seismic structure, and the layer isolation is better than the foundation isolation.

\subsection{Nonlinear material model}

In the finite element analysis of reinforced concrete structure, due to many nonlinear factors, to consider these nonlinear factors, many parameters are often introduced, and these parameters may affect each other, some are difficult to determine directly by test, coupled with the complexity and dispersion of the coagulation material itself, the mechanism of some fracture and failure is not completely clear, therefore, the nonlinear analysis results of structures often show a large range of changes. For this reason, a variety of material simplified models are usually used for analysis.

An isotropic modulus with a variable modulus $E(t)$ is used to simulate the nonlinear characteristics of concrete materials. For the stress-strain relationship of isotropic linear elastomers the equation is as follows (7):

$$
\sigma_{i j}=\frac{E}{1+\mu} \varepsilon_{i j}+\frac{\mu \mathrm{E}}{(1+\mu)(1-2 \mu)} \varepsilon_{k k} \delta_{i j}
$$

Where the elastic modulus and Poisson's ratio $\mu$ are constant. Replace the elastic modulus $E$ in the equation with tangent elastic modulus $E(t)$, and obtain the relationship between the stress increment $d \sigma_{i j}$ and the strain component, equation is as follows:

$$
d \sigma_{i j}=\frac{\mathrm{E}(t)}{1+\mu} d \varepsilon_{i j}+\frac{\mu \mathrm{E}(t)}{(1+\mu)(1-2 \mu)} d \varepsilon_{k k} \delta_{i j}
$$

For concrete, when the compressive stress does not exceed $75 \%$ of the compressive strength, $\mu$ is constant, when the stress is further increased, $\mu$ value will gradually increase. Therefore, in general, the nonlinearity of materials can be reflected by the numerical variation of $E(t)$. According to the uniaxial test results, the tangential elastic modulus can be obtained by using the relationship between equivalent stress and equivalent strain. The stress-strain relationship can be expressed by hyperbola, parabola, or exponential curve. 
(1) The stress-strain relationship under monotonic axial compression

Saenz's formula is widely used, the equation is as follows:

$$
\sigma=\frac{\mathrm{E} \varepsilon}{a+b\left(\frac{\varepsilon}{\varepsilon_{c}}\right)+c\left(\frac{\varepsilon}{\varepsilon_{c}}\right)^{2}+d\left(\frac{\varepsilon}{\varepsilon_{c}}\right)^{3}}
$$

Where $\mathrm{F}$ is the modulus of elasticity and $a, b, c$, and $d$ are constants.

$a, b, c$, and $d$ are determined by:

1. $\varepsilon=0, d \sigma / d \varepsilon=\mathrm{E}_{0}$;

2. $\varepsilon=\varepsilon_{c}, \sigma=R_{c}$;

3. $\varepsilon=\varepsilon_{c}, d \sigma / d \varepsilon=0$;

4. $\varepsilon=\varepsilon_{u}$ (ultimate strain), $\sigma=\sigma_{u^{\circ}}$

After the coefficients $a, b, c$, and $d$ are determined by the above conditions, it can be obtained, the equation is as follows:

$$
\begin{gathered}
\sigma=\frac{\mathrm{E}_{0} \varepsilon}{1+\left(R+\frac{E_{0}}{E_{s}}-2\right) \frac{\varepsilon}{\varepsilon_{c}}-(2 R-1)\left(\frac{\varepsilon}{\varepsilon_{c}}\right)^{2}+R\left(\frac{\varepsilon}{\varepsilon_{c}}\right)^{3}} \\
R=\frac{\left(\mathrm{E}_{0} / \mathrm{E}_{s}\right)\left(R_{c} / \sigma_{u}-1\right)}{\left(\varepsilon_{u} / \varepsilon_{c}-1\right)^{2}}-\frac{\varepsilon_{c}}{\varepsilon_{u}}
\end{gathered}
$$

If condition 4 is ignored, that is, the descending segment of the curve is ignored, then the equation is as follows:

$$
\sigma=\frac{\mathrm{E}_{0} \varepsilon}{1+\left(\frac{\mathrm{E}_{0}}{\mathrm{E}_{\mathrm{s}}}-2\right) \frac{\varepsilon}{\varepsilon_{c}}+\left(\frac{\varepsilon}{\varepsilon_{c}}\right)^{3}}
$$

\section{(2) Stress-strain relationship under monotone axial tension loading}

Because the tensile strength of concrete is low, and relative to the tensile strength, the proportional limit is relatively high, so in the calculation, it is assumed that the stressstrain relationship of concrete under tension is a straight line until the tensile break, concrete cracks when the stress reaches its tensile strength. It is assumed that the elastic modulus under tension is equal to the initial elastic modulus under compression. Stress-strain relationship of concrete before cracking equation is as follows:

$$
\sigma_{i}=\mathrm{E}_{0} \varepsilon_{t}
$$

There are three types of nonlinear finite element models for reinforced concrete structures: separated, combined, and integrated.

There are various longitudinal and transverse bars in reinforced concrete members. However, in the dynamic analysis of complex structures, if the concrete and steel bars are divided into sufficiently small units by a separate calculation model, although it is feasible in theory and can take into account the bonding and slip between reinforcement and concrete, it requires a large amount of computing resources, which is often difficult to achieve in real calculation. The combined model includes the layered combined model which is suitable for the bar system, the combined model with film, or the combined model with reinforcement which is suitable for the two-or three-dimensional structure. Although concrete is a heterogeneous material from the microscopic point of view, but the size of the structure is more than four times, the size of coarse aggregate it is often regarded as a homogeneous material for macro stress analysis. In this way, the integral finite element model can be adopted, that is, the reinforcement is assumed to be dispersed in the whole element, and the element is regarded as a continuous and uniform material, thus, the element stiffness matrix of concrete and steel bar is obtained, and the integral finite element model is used in this paper.

\subsection{Comparison of displacement between isolation layer and top layer}

1. Under the action of Taft wave, the displacement of the top layer of the aseismic structure is $40.23 \mathrm{~mm}$, and the displacement of the bottom layer is 0 at the fixed end, and the displacement difference between the top layer and the bottom layer is $40.23 \mathrm{~mm}$. The displacement of the top layer of the base isolation structure is $34.49 \mathrm{~mm}$, the displacement of the isolation layer is $10.51 \mathrm{~mm}$, and the displacement difference between the top layer and the isolation layer is 23.98 $\mathrm{mm}$. The displacement of the top layer of the layer isolation structure is $30.30 \mathrm{~mm}$, the displacement of the isolation layer is $18.28 \mathrm{~mm}$, the displacement of the bottom layer is 0 , and the displacement difference between the top layer and the isolation layer is $12.02 \mathrm{~mm}$. Aseismatic structure has a larger displacement difference than isolation and is more likely to be damaged by tensile crack. There is little difference between the displacement of the top layer and the isolation layer of the isolation structure. The main structure is in a translational state, and the effect of floor isolation is more obvious.

2. Under the action of Taft wave in rare earthquakes, the displacement of the top layer of the seismic structure is $89.68 \mathrm{~mm}$, the displacement of the bottom layer is 0 , and the displacement difference between the top layer and the bottom layer is $89.68 \mathrm{~mm}$ [17]. The displacement of the top layer of the base isola- 
tion structure is $110.3 \mathrm{~mm}$, the displacement of the isolation layer is $39.83 \mathrm{~mm}$, and the displacement difference between the top layer and the isolation layer is $70.47 \mathrm{~mm}$. The displacement of the top layer of the layer isolation structure is $73.07 \mathrm{~mm}$, the displacement of the isolation layer is $55.49 \mathrm{~mm}$, the displacement of the bottom layer is 0 , and the displacement difference between the top layer and the isolation layer is $17.58 \mathrm{~mm}$. According to the code, the maximum horizontal deformation of LRB600 and LRB700 is $286.96 \mathrm{~mm}$ and $334.78 \mathrm{~mm}$, respectively, so the displacement of the isolation layer meets the requirements of the code [18]. The lateral displacement of the main structure is $70.47 / 49500<1 / 550$ at the rare intensity of Taft wave, which is less than the limit value of elastic displacement angle, and the main structure is in the elastic stage. Aseismatic structure displacement difference is larger than isolation, easy to rupture damage [19].

\subsection{Acceleration response}

Figure 4 shows the top-level acceleration diagram of various structural models at $0 \sim 20$ s under the action of multiple and rare earthquakes of Taft wave. As can be seen from the figure, under the action of multiple earthquakes, the acceleration amplitude of the top floor of the earthquakeresistant structure is $1118 \mathrm{~mm} / \mathrm{s}^{2}$, the acceleration amplitude of the top floor of the base-isolated structure is 988.6 $\mathrm{mm} / \mathrm{s}^{2}$, and that of the story-isolated structure is 855.3 $\mathrm{mm} / \mathrm{s}^{2}$. The acceleration of the top floor of base isolation and story isolation is 0.12 and 0.24 of the seismic structure, respectively [20]. Under the action of rare earthquakes, the amplitude of acceleration at the top of the aseismatic structure is $3084 \mathrm{~mm} / \mathrm{s}^{2}$, the amplitude of acceleration at the top of the base-isolated structure is $2834 \mathrm{~mm} / \mathrm{s}^{2}$, and the amplitude of acceleration at the top of the story isolation structure is $2577 \mathrm{~mm} / \mathrm{s}^{2}$.

The acceleration of the top layer of base isolation and story isolation is 0.08 and 0.16 , respectively, of the seismic structure [21]. According to the data analysis, under the action of Taft wave, the acceleration response of each structure in the whole process under the earthquake action is smaller than that of the seismic structure, and the seismic energy is dissipated in the isolation layer [22]. The acceleration response of the layer isolation structure is smaller than that of the base isolation structure. The seismic isolation effect of this frame structure is better than others [23].

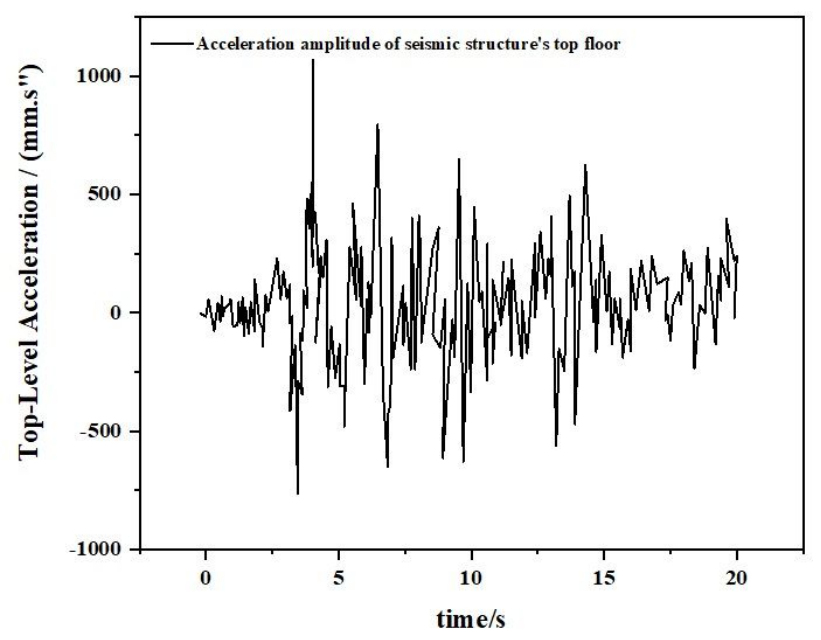

Figure 4: Top level acceleration in frequent earthquakes

\subsection{Base shear}

As can be seen from Table 3, under the action of multiple earthquakes, the base shear of foundation isolation is $1208.06 \mathrm{kN}$ and the floor isolation is $926.43 \mathrm{kN}$, which are 0.37 and 0.3 of the base shears of the aseismic structure respectively. Under the action of rare earthquakes, the base-isolation shear is $4039.59 \mathrm{kN}$, and the story isolation shear is $3119.99 \mathrm{kN}$, which are, respectively, 0.4 and 0.31 of the base-isolation shears of the astigmatic structure [24]. The effect of floor isolation is slightly lower than that of the base isolation structure, so the effect is slightly better than that of the base isolation structure, and far better than that of the seismic structure [25]. The seismic safety has been effectively improved, but whether the seismic intensity can be reduced still needs further study.

Table 3: Base shear force of structure

\begin{tabular}{cccccc}
\hline \multicolumn{2}{c}{ In the earthquake $\left(A_{\max }=70 / \mathrm{cm} / \mathrm{s}^{2}\right)$} & \multicolumn{3}{c}{ Severe earthquake $\left(A_{\max }=400 / \mathrm{cm} / \mathrm{s}^{2}\right)$} \\
The seismic & Base isolation & Layer interval shock & The seismic & Base isolation & Layer interval shock \\
\hline 3039.33 & 1208.06 & 926.43 & 6768.25 & 2739.59 & 2119.99 \\
\hline
\end{tabular}




\section{Conclusions}

In this paper, the development of aseismic design theory of building structures and two nonlinear analysis methods based on performance design are reviewed and summarized. The nonlinear time-history analysis is close to the original structure, so it is reasonable and reliable. Compared with the superstructure of base-isolated building, the displacement between floors is smaller and the comfort is better. Seismic safety has been significantly enhanced; however, it has to be seen whether the seismic intensity level can be reduced. Using the fuzzy set theory to evaluate the fuzziness of the seismic performance of the overlimit high-rise building structure can not only reflect the actual situation of the seismic performance of the core tube of the shaped steel concrete frame, but also make the qualitative description quantitative. The high uncertainty of earthquake disasters, as well as the new characteristics of large economic losses caused by modern earthquake disasters, has prompted deep reflection in the world's earthquake engineering community. It is necessary to continue to explore more perfect ideas and methods of structural a seismic design, which is also the basis of control. The method shows strong operability, easy to achieve results, and can be widely used in general engineering evaluation

Funding information: The authors state no funding involved.

Author contributions: All authors have accepted responsibility for the entire content of this manuscript and approved its submission.

Conflict of interest: The authors state no conflict of interest.

\section{References}

[1] Rohman F, Leman S. Effects of opening dimension of shear wall on the behavior of high-rise building structure due to earthquake load. IOP Conf Ser: Mater Sci Eng. 2020;1007:012055 https://doi.org/10.1088/1757-899X/1007/1/012055.

[2] Jagota V, Sethi AP, Kumar K. Finite Element Method: An Overview. Walailak J Sci Technol. 2013;10(1):1-8.

[3] Shim HB, Kim Y, Park HS. Verification of structural performance of connections between reinforced concrete shear wall and outriggers in high-rise buildings. Struct Concr. 2019;20(3):932-41.

[4] Xiao Y, Bhola J. Design and optimization of prefabricated building system based on BIM technology. Int J Syst Assur Eng Manag. 2021 https://doi.org/10.1007/s13198-021-01288-4.
[5] Sun Y, Li H, Shabaz M, Sharma A. Research on building truss design based on particle swarm intelligence optimization algorithm. Int J Sys Assur Eng Manag. 2021. https://doi.org/10.1007/s13198. 021-01192-x.

[6] Zhang H, Li F, Tai J, Zhou J. Research on structural design of an isolated high-rise building with enlarged base and multiple tower layers in high-intensity area. Math Probl Eng. 2021;2021(12):114.

[7] Song Y, He W, He X, Han Z. Vibration control of a high-rise building structure: theory and experiment. IEEE/CAA J Autom Sin. 2021;8(4):866-875 https://doi.org/10.1109/JAS.2021.1003937.

[8] Kamaludin P, Kassem MM, Farsangi EN, Tan CG, Nazri FM. Assessment of seismic scenario-structure based limit state criteria for a reinforced concrete high-rise building. IOP Conf Ser Mat Sci Eng. 2020;920:012012 https://doi.org/10.1088/1757899X/920/1/012012.

[9] Yao Q, Shabaz M, Lohani TK, Wasim Bhatt M, Panesar GS, Singh RK. 3D modelling and visualization for Vision-based Vibration Signal Processing and Measurement. J Intell Syst. 2021;30(1):541-53.

[10] Lu S. Optimization of object-oriented 3d cad preprocessing system for steel structure of high-rise buildings. Comput Aided Des Appl. 2020;18 S3:106-17.

[11] Kumar A, Jagota V, Shawl RQ, Sharma V, Sargam K, Shabaz M, et al. Wire EDM process parameter optimization for D2 steel. Mater Today Proc. 2021;37(2):2478-82.

[12] Solovyova V, Abu-Khasan M, Solovyov D.Thin-walled building structures with improved properties for highrise construction. MATEC Web Conf. 2019;265: 05004 https://doi.org/10.1051/matecconf/201926505004.

[13] Bharti R, Khamparia A, Shabaz M, Dhiman G, Pande S, Singh P. Prediction of Heart Disease Using a Combination of Machine Learning and Deep Learning. Comput Intell Neurosci. 2021 Jul;2021:8387680.

[14] Lu Z, Zhang H, Masri SF. Studies on vibration control effects of a semi-active impact damper for seismically excited nonlinear building. Smart Struct Syst. 2019;24(1):95-110.

[15] Monika F, Zega BC, Prayuda H, Cahyati MD, Putra YA. The effect of horizontal vulnerability on the stiffness level of reinforced concrete structure in high-rise buildings. J Civil Eng Forum. 2020;6(1):49-60.

[16] Li L, Song G, Ou J. Hybrid active mass damper (AMD) vibration suppression of nonlinear high-rise structure using fuzzy logic control algorithm under earthquake excitations. Struct Contr Health Monit. 2010;18(6):698-709.

[17] Azizi M, Ejlali RG, Mousavi Ghasemi SA, Talatahari S. Upgraded Whale Optimization Algorithm for fuzzy logic based vibration control of nonlinear steel structure. Eng Struct. 2019;192:53-70.

[18] Pourzeynali S, Zarif M. Multi-objective optimization of seismically isolated high-rise building structures using genetic algorithms. J Sound Vibrat. 2008;311(3-5):1141-60.

[19] Jairath K, Singh N, Jagota V, Shabaz M. Compact Ultrawide Band Metamaterial-Inspired Split Ring Resonator Structure Loaded Band Notched Antenna. Math Probl Eng. 2021;2021:1-12.

[20] Wang Q, Qiao H, De Domenico D, Zhu Z, Tang Y. Seismic response control of adjacent high-rise buildings linked by the Tuned Liquid Column Damper-Inerter (TLCDI). Eng Struct. 2020;223:111169.

[21] Li Z, Adeli H. Control methodologies for vibration control of smart civil and mechanical structures. Expert Syst. 2018;35(6):e12354. 
[22] Rusanova E, Abu-Khasan M. (2019). Durable geoecoprotective building structures from ash foam concrete for high-rise construction. MATEC Wen Conf. 2019;265:05006. https://doi.org/10.1051/matecconf/201926505006.

[23] Li S, Wu C, Kong F. Shaking table model test and seismic performance analysis of a high-rise RC shear wall structure. Shock Vib. 2019;2019(3):1-17.
[24] Hou JM, Li XJ, Yuan Y, Ren ZY, Zhao LD, Wang ZC, et al. ScenarioBased Tsunami Evacuation Analysis: A Case Study of Haimen Town, Taizhou, China. J Earthq Tsunami. 2017;11(03):1750008.

[25] Wang Q, Qiao H, De Domenico D, Zhu Z, Tang Y. Seismic performance of optimal Multi-Tuned Liquid Column Damper-Inerter (MTLCDI) applied to adjacent high-rise buildings. Soil Dyn Earthq Eng. 2021;143:106653. 